\title{
The Frequency of Common Allergens in Allergic Rhinitis among the Patients Referred to the Allergy Clinic of Qods Hospital in Qazvin during 2007-2010
}

\author{
Manuchehr Mahram ${ }^{1}$, Ameneh Barikani ${ }^{2 *}$ and Negin Nejatian ${ }^{3}$
}

${ }^{1}$ Department of Pediatrics, Qazvin University of Medical Sciences, Qazvin, Iran

${ }^{2}$ Department of Social Medicine, Qazvin University of Medical Sciences, Iran

${ }^{3}$ General physician, Qazvin University of Medical Sciences, Iran

\begin{abstract}
Introduction: Allergic respiratory diseases such as allergic rhinitis are highly prevalent throughout the world. Allergens or allergic agents are considered as the agents causing or exacerbating such diseases.

Objective: Identifying and determining the frequency of common aeroallergens in allergic rhinitis in Qazvin.

Materials and methods: In this descriptive-analytical study, all patients with allergic rhinitis referred to the allergy clinic of Qods hospital in Qazvin during 2007-2010 were examined through skin prick test with 11 aeroallergens. The data on age, gender, patients' referring season, and skin test results were recorded in the questionnaire and test sheet. The data so collected was analyzed by SPSS16 using Chi-square tests, student's $t$-test, and Fisher's exact test with a significant level of $\mathrm{P}<0.05$.

Findings: 163 patients were included in the study. The average age of patients was $24.6 \pm 1.26$ and the ratio of women to men was $1.3 .69 .3 \%$ of them showed positive skin test at least to one of the allergens under study. The highest sensitivity to weed pollens (Russian thistle) was found to be $58.9 \%$ and then to grass (12 grasses) with $28.9 \%$, birch tree with $26.7 \%$, and wheat with $14.4 \%$ from among plant aeroallergens. Beetle with $42.2 \%$, Alternaria fungus with $26.7 \%$, cat with $25.6 \%$, mite D.P with 21.1 , mite D.F with $20 \%$, penicillium fungus with $15.6 \%$, and feather with $14.4 \%$ from among non-plant aeroallergens were at the next levels respectively.
\end{abstract}

Conclusions: The highest prevalence of allergy was seen to weed pollens (Russian thistle), grass (12 grasses), beetle and alternaria fungus.

Keywords: Allergen; Allergic rhinitis; Skin prick test; Pollen; Russian thistle; Grass; Beetle; Alternaria fungus

\section{Introduction}

Respiratory allergy is a common allergy among all populations throughout the world. Reviewing epidemiological data available all over the world, one could perceive the importance of this issue. Epidemiological studies obtained from different countries shows the prevalence of respiratory allergy as $15-30 \%$ [1]. In an allergic population, sensitivity in urban areas is greater than in rural areas [2]. An increase in the prevalence of atopic diseases has been recorded in most tropical countries as attributed to factors such as increasing urbanization. This may change facing environmental allergens and individual susceptibility to allergic disorders.

Aeroallergens (airborne allergens) play an important role in respiratory allergic diseases, especially asthma and allergic rhinitis.

Sampling from aeroallergens provides information that is clinically useful in determining possible reason for allergic symptoms in sensitive people [3]. Aeroallergens including pollens (plant pollens), fungi, body covering of animals, domestic mites, domestic animals, and insects, are the most important factors initiating allergic diseases.

Pollen is the male gametophyte of seed-bearing plants resembling dust particles. One of the most obvious features of pollen allergies is their seasonal nature. Each spring, summer, and autumn, pollens are released from trees, grasses and weeds that find their way through the nose and bronchial airways. People experience allergic symptoms only when the pollen particles are distributed in the air, and the major risk factor is family history of positive atopy.

Various pollens causing allergic reactions are produced mostly by flowerless plants such as trees, grasses and weeds. Grasses are important factors for allergic reaction associated with $\mathrm{IgE}$ around the world.

One of the most common types of respiratory allergic diseases is allergic rhinitis with a prevalence rate of $20-40 \%$ [4]. Allergic rhinitis is one of the most prevalent chronic states that are common $10-30 \%$ in adults and up to $40 \%$ in children [5]. Therefore, maximum prevalence of such disease has been observed at youth ages; however, it's also a remarkable issue in adults.

Allergic rhinitis is considered as a health issue and problem in the world [6]. There is some evidence for its increased prevalence in recent decades. This increase has been reported in both children and adults.

This disease is sometimes mistakenly considered as a mild disease, while its symptoms may significantly affect patients' quality of life through causing fatigue, headache, cognitive disorder, effect on physiological health and other systemic symptoms.

Allergic rhinitis is closely associated with the release of $\mathrm{TH} 2$

*Corresponding author: Ameneh Barikani, Department of Social Medicine Qazvin University of Medical Sciences, Iran, E-mail: barikani.a@gmail.com

Received January 31, 2013; Accepted February 20, 2013; Published February 21, 2013

Citation: Mahram M, Barikani A, Nejatian N (2013) The Frequency of Common Allergens in Allergic Rhinitis among the Patients Referred to the Allergy Clinic of Qods Hospital in Qazvin during 2007-2010. J Aller Ther 4: 130. doi:10.4172/21556121.1000130

Copyright: (c) 2013 Mahram M, et al. This is an open-access article distributed under the terms of the Creative Commons Attribution License, which permits unrestricted use, distribution, and reproduction in any medium, provided the original author and source are credited. 
type immune response, antigen-presenting cells (APC), eosinophils, basophils, and macrophages as main cellular elements and IgE as well as all other mediators such as histamine, leukotrienes and interleukins, granulocyte-macrophage colony-stimulating factor (GM-CSF) and various chemokines. Moreover, pollen is considered as one of the most abundant and inevitable elements in allergic rhinitis [2].

Skin prick test is one of the most common methods [1]. Skin test reactivity to aeroallergens is a tool for respiratory allergy that is generally accepted and used in epidemiological studies [7]. This method does not require spending long time and high cost, and compared to the same experiments, its sensitivity and features are very high. This test can play a determining role in adopting prevention methods and patients' treatment and desensitization. Usually, positive skin reactions rate is highly associated with clinical findings and it can even determine the severity of the disease. Avoiding allergens shall be considered as the first-line prevention in controlling allergic rhinitis; even when it is not completely effective. This method may reduce the need for further treatment. Identifying the most common aeroallergens to which the patients are allergic plays an important role in diagnosis and treatment of allergic rhinitis. Selecting the most appropriate allergen extracts for diagnostic test and finding the best formulation for allergen immunotherapy depend on data on the most important aeroallergens in a specific area.

The prevalence of allergic rhinitis may be different both inside and between countries. This difference is attributed to the level or total load of aeroallergens. The prevalence of different aeroallergens has been determined in the studies conducted in other parts of the world. Different allergens play different roles depending on environmental conditions of each region, such as climate, population, and level of exposure [1]. Identifying the aeroallergens of each region help prevent allergic rhinitis disease in an advisable time, while it is effective in selecting the type of allergy vaccine for appropriate treatment when prevention and medical treatment are not effective and allergy vaccines are required.

For the above reasons, we decided to study the prevalence of allergens and its relationship with allergic rhinitis in our own region (city of Qazvin).

\section{Methodology}

By conducting a descriptive-analytical epidemiology, all patients referred to the allergy clinic of Qods hospital in Qazvin during 20072010 and diagnosed with allergic rhinitis (clinical symptoms including sneezing, runny nose, itching or nasal congestion along with eye or throat involvement with the confirmation of skin allergy test) were studied.

The inclusion criteria included referring to the allergy clinic of Qods hospital complaining of sneezing, runny nose, itching or nasal congestion along with eye or throat involvement and diagnosis of allergic rhinitis, filing at allergy clinic, performance of requested examinations and continuous follow-up visits.

The exclusion criteria included underlying diseases such as colds, acute and chronic sinusitis and/or all other types of allergic rhinitis such as vasomotor and infectious rhinitis, taking antihistamine and corticosteroid drugs over the past two weeks, and heart disease. In this study, the skin test with 11 aeroallergens was performed on all patients with conditions mentioned above, who referred to the allergy clinic of Qods hospital in Qazvin.
Firstly, patients were asked about their history and then the examination was performed. The requested examinations for patients included CBC, ESR, BS and BUN. Sinuses radiography was also requested for patients in order to diagnose acute and chronic sinusitis.

Those patients with no underlying diseases such as colds, acute and chronic sinusitis and/or all other types of allergic rhinitis such as vasomotor rhinitis, infectious rhinitis and heart disease were tested. They had also discontinued the use of antihistamine and corticosteroid drugs two weeks before the test.

Before doing the test, the patients were provided with a consent form and a Research scientific details and informative sheet and, the consent form was filled by the patients.

The skin test was considered valuable if the patients had a positive reaction to histamine (positive control) with edema greater than $3 \mathrm{~mm}$ and erythema greater than $10 \mathrm{~mm}$, and a negative reaction to normal saline with edema and erythema about zero. Otherwise, they were excluded from the study.

The skin test was performed using allergen extracts manufactured by Stallergene (Anthony France) Company in France.

While performing the tests, the used kits were frequently checked for expiry date. The tests were performed and the result was declared by a qualified expert with several years of experience working in the allergy clinic of Qods hospital under the supervision of the relevant physician.

The tested aeroallergens consisted of 11 allergens including plant aeroallergens such as grass (12 grasses: Bent grass, Bemuda grass, Cocksfoot, Meadow Fescue, Meadow grass, Oat grass, Rye grass, Sweetvernal grass, Timothy grass, Wild Oat, Yorkshire Fog, Bromus), Russian thistle, wheat, and birch tree. Non-plant aeroallergens were also tested such as cat, beetle, feather, D. Farinae and D. Pteronyssinus mites, Penicillium fungus, and Alternaria fungus. These allergens were selected based on clinical experience and according to the phytogeography conditions of Qazvin city.

The above-mentioned extracts were put on the skin of both forearms with at least $2 \mathrm{~cm}$ distance from each other, and prick test was performed using a lancet device. The skin reaction was measured on site after 15-20 minutes through formation of skin erythema and edema.

Edema, with a diameter of more than $3 \mathrm{~mm}$ and erythema with a diameter of more than $10 \mathrm{~mm}$ was considered as a positive skin reaction. The test results were recorded on the sheet related to skin test.

Patients' data such as demographic information, history, examination and test results as well as file number, patients' address and phone number were collected in the questionnaire attached to the skin test form.

Information about the disease, demographic specification of patients and skin test results were extracted from the records and were then statistically analyzed through SPSS 16, Chi-square test and Fisher's exact test. P-values less than 0.05 were considered as a significant relationship between the variables.

Before performing the skin test, the consent forms were completed by the patients. Apart from skin test to detect disease-causing agents, additional costs were avoided to impose on the patients. 


\section{Results}

In this study, the questionnaire and skin test form were completed for 180 individuals, among whom 17 patients were excluded from the study after final reviews due to underlying diseases or not returning for follow-up visit. Finally, 163 patients were included in the study. From among these patients, in addition to rhinitis, 18 patients had asthma, 16 patients had dermatitis (atopic dermatitis and hives) and 5 patients had all three diseases.

Among all these people, $57.7 \%$ were female whose average age was $24.6 \pm 1.26$.

Reviewing skin test results showed that $69.3 \%$ of these patients had positive skin test to at least one of allergens under study.

On average, patients' sensitivity to various allergens was in terms of $1.9 \pm 2.23$ substances of total 11 reviewed substances in the test (a minimum of zero and a maximum of 11 substances). Figure 1 shows the classification of these patients' sensitivity status to allergens in terms of the number of allergens. The results of this study show that the rate of sensitivity to Russian thistle has the highest prevalence rate $(58.9 \%)$. Most referring cases were in the summer (39.3\%) (Figure 2).

There is a significant relationship between wheat, cat, beetle, mite D.P, mite D.F allergens, and patients' age so that the highest prevalence of allergen of wheat was at ages 21-30 and allergens of cat, beetle and mite at ages 31-40 have the highest level of prevalence (Tables 1-3).

\section{Discussion and Conclusion}

The results of the recent research showed that $69.3 \%$ of the patients

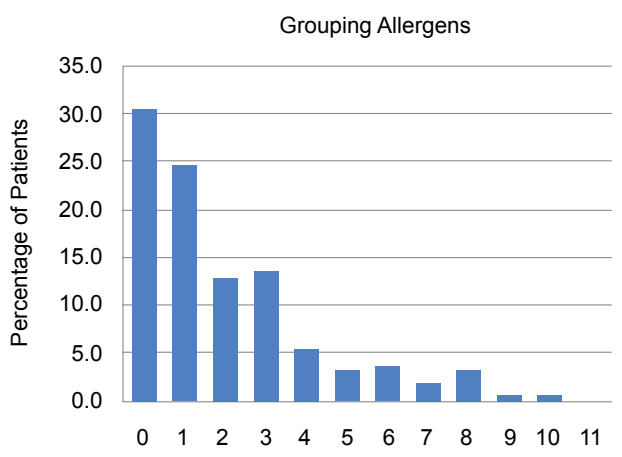

Figure 1: Frequency distribution of sensitivity different allergens in terms of the quantity of allergens in patients referred to allergy clinic of Qods hospital in Qazvin during 2007-2010 complaining of allergic rhinitis.

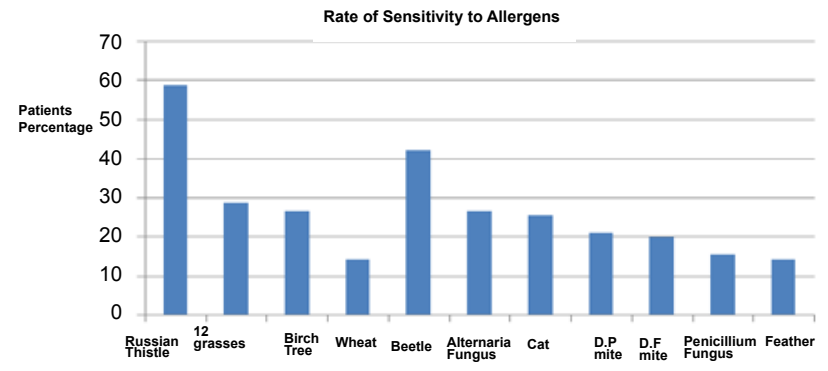

Figure 2: Frequency distribution of sensitivity different allergens in patients referring to the allergy clinic of Qods hospital in Qazvin during 2007-2010 complaining of allergic rhinitis.

\begin{tabular}{|c|c|c|}
\hline Referring Season & $\begin{array}{c}\text { Number of referred } \\
\text { patients per season }\end{array}$ & $\begin{array}{c}\text { Percentage of number of } \\
\text { patients referred per season }\end{array}$ \\
\hline of total & & 19.6 \\
\hline Spring & 32 & 39.3 \\
\hline Summer & 64 & 17.8 \\
\hline Autumn & 29 & 23.3 \\
\hline Winter & 38 & 100 \\
\hline Total & 163 & \\
\hline
\end{tabular}

Table 1: Frequency distribution of patients referring to the allergy clinic of Qods hospital in Qazvin during 2007-2010 complaining of allergic rhinitis in terms of season.

\begin{tabular}{|c|c|c|c|c|}
\hline \multirow{2}{*}{$\begin{array}{c}\text { Type of allergen/ } \\
\text { Sensitivity }\end{array}$} & \multicolumn{2}{|c|}{ Gender } & \multirow{2}{*}{ Total } & P-Value \\
\cline { 2 - 3 } & $\begin{array}{c}\text { Female } \\
\mathbf{( N = 9 4 )}\end{array}$ & $\begin{array}{c}\text { Male } \\
\mathbf{( N = 6 9 )}\end{array}$ & & \\
\hline Russian Thistle & $31(62)$ & $22(55)$ & $53(58.9)$ & 0.324 \\
\hline Grass (12 grass) & $15(27.3)$ & $11(31.4)$ & $26(28.9)$ & 0.424 \\
\hline Birch Tree & $13(24.5)$ & $11(29.7)$ & $24(26.7)$ & 0.377 \\
\hline Wheat & $11(20)$ & $2(5.7)$ & $13(14.4)$ & 0.054 \\
\hline Beetle & $21(40.4)$ & $17(44.4)$ & $38(42.2)$ & 0.421 \\
\hline Alternaria & $12(24)$ & $12(30)$ & $24(26.7)$ & 0.344 \\
\hline Cat & $11(20.4)$ & $12(33.3)$ & $23(25.6)$ & 0.129 \\
\hline Mite D.P & $11(20.4)$ & $8(22.2)$ & $19(21.1)$ & 0.517 \\
\hline Mite D.F & $11(20.4)$ & $7(19.4)$ & $18(20)$ & 0.568 \\
\hline Penicillium & $5(10.2)$ & $9(22)$ & $14(15.6)$ & 0.108 \\
\hline Feather & $8(14.8)$ & $5(13.9)$ & $13(14.4)$ & 0.578 \\
\hline
\end{tabular}

Table 2: Frequency distribution of sensitivity different allergens in patients referred to the allergy clinic of Qods hospital in Qazvin during 2007-2010 in terms of gender.

under study had positive skin test to at least one of the studied allergens. These patients were more sensitive to plant allergens than other allergens, especially to weed.

The results of conducted studies in patients with allergic rhinitis, asthma and/or both in Karaj, Shiraz, Isfahan, and Mashhad showed that $68 \%, 62.2 \%, 82 \%, 85 \%$, and $81 \%$ of the patients had positive skin reaction to at least one of the 10-15 studied allergens [7-11] respectively. In this study, positive skin test to beetle was $42.2 \%$. Beetle families have been reported as allergen and their commonest symptoms are skin lesions [12-14], respiratory [15] and eye [16] allergy. In Iran, We have beetles that are medically important, but a few reports are available. The majority of insect-induced dermatitis are in the northern province, Fars, Hamadan and Hormozgan provinces respectively [17].

In the studies conducted in other parts of the world, positive skin reaction to at least one allergen in $55-97 \%$ of the patients was observed [8,18-29].

The differences observed in the frequency of cases with positive skin test in the studies mentioned above could be due to the difference in type and number of the allergens under study and type and the patients' severity of the underlying disease. As the results of this investigation revealed, the frequency of cases with positive skin test to plant allergens of Russian thistle (as a type of weed) was higher. This finding is consistent with the results of the studies conducted in Mashhad and Isfahan $[10,11]$.

In a study conducted in Shiraz, the most common skin reaction was first to grass, and the second to weed [7]. In Karaj, the frequency of positive skin reaction to herbaceous grass was reported to be higher than other allergens [9]. In another investigation conducted in Tehran and Karaj, the most common pollen causing positive skin reaction was mentioned as chenopod or lambsquarter. In a study carried out in Zanjan, the highest sensitivity was found to rye grass [8]. 


\begin{tabular}{|c|c|c|c|c|c|c|}
\hline \multirow[t]{2}{*}{ Type of allergen/Sensitivity } & \multicolumn{4}{|c|}{ Referring Season } & \multirow[t]{2}{*}{ Total } & \multirow[t]{2}{*}{ P-Value } \\
\hline & Spring & Summer & Autumn & Winter & & \\
\hline Russian Thistle & $7(46.7)$ & $25(67.6)$ & $8(53.3)$ & $13(56.5)$ & $53(58.9)$ & 0.508 \\
\hline Grass (12 Grass) & $5(33.3)$ & $7(18.9)$ & $7(35)$ & $7(38.9)$ & $26(28.9)$ & 0.366 \\
\hline Birch Tree & $7(41.2)$ & $4(13.3)$ & $5(29.4)$ & $8(30.8)$ & $24(26.7)$ & 0.183 \\
\hline Wheat & $3(16.7)$ & $3(6.5)$ & $2(11.1)$ & $6(26.1)$ & $13(14.4)$ & 0.225 \\
\hline Beetle & $5(33.3)$ & $12(41.4)$ & $6(27.3)$ & $15(62.5)$ & $38(42.2)$ & 0.088 \\
\hline Alternaria & $3(20)$ & $5(15.2)$ & $1(7.7)$ & $15(51.7)$ & $24(26.7)$ & 0.003 \\
\hline Cat & $5(33.3)$ & $6(20)$ & $4(18.2)$ & $8(34.8)$ & $23(25.6)$ & 0.454 \\
\hline Mite D.P & $1(7.1)$ & $4(13.8)$ & $4(19)$ & $10(38.5)$ & $19(21.1)$ & 0.062 \\
\hline Mite D.F & $3(23.1)$ & $2(6.9)$ & $4(18.2)$ & $9(34.6)$ & $18(20)$ & 0.082 \\
\hline Penicillium & $3(20)$ & $3(8.8)$ & $2(11.8)$ & $6(25)$ & $14(15.6)$ & 0.360 \\
\hline Feather & $3(23.1)$ & $1(3.3)$ & $4(18.2)$ & $5(20)$ & $13(14.4)$ & 0.199 \\
\hline Total & $45(16.9)$ & $71(26.8)$ & $47(17.8)$ & $102(38.5)$ & $265(100)$ & \\
\hline
\end{tabular}

Table 3: Frequency distribution of sensitivity to different allergens in patients referring to the allergy clinic of Qods hospital in Qazvin during $2007-2010$ in terms of referring season.

The findings of another research performed on 99 patients aged 2-15 with asthma and rhinitis in Tehran and Karaj revealed that positive skin reaction to mite (D.P and D.F) is more common than that to other allergens such as pollens. This could be due to the fact that this age group is more exposed to indoor allergens [8].

The results of another study in Thailand showed that patients were more sensitive to domestic allergens including mite and beetle, respectively than to other allergens. In the investigations conducted in Singapore and Malaysia, the frequency of positive skin reaction to domestic allergens was also higher. In a joint study in Ankara in Turkey and Seoul, it was found that the highest frequency of positive skin reaction is to grass and mite, respectively [27]. The results of the studies conducted in Spain indicated that there is more sensitivity (allergy) to olive than to other allergens [29]. A study was also conducted in Japan as indicative of the highest rate of positive skin test to cedar.

These differences show that climatic and geographical differences could be effective in the incidence of skin reaction to an allergen.

During this study, no statistically significant difference was found between the rate of positive skin reaction to allergens and patients' gender. This finding was consistent with the results of the study conducted on 500 patients to 7 allergens in France, and it was inconsistent with the studies conducted in Shiraz and Isfahan $[7,10]$.

In the studies conducted in Zanjan, with the exception of sensitivity to feather that was significantly higher in women than in men, no significant difference about other studied allergens was observed between women and men.

This study indicated that there is a significant relationship between wheat, cat, beetle, mite D.P, mite D.F allergens, and patient's age. The study conducted in Zanjan also showed that the rate of sensitivity to crap and grass in patients aged less than or equal to 20 years is significantly higher than other age groups [8]. The results of the study conducted in Shiraz did not show any significant difference between frequency rate of positive skin reaction in various age groups [7]. However, in the study of Benzarti et al. and regardless of the type of allergen, the rate of positive skin reaction in the age group of $15-35$ has been higher than other age groups [28]. Moreover, in the study conducted in Jordan, the prevalence of cat and mite D.P allergens is higher in younger patients [30].

According to the results of this study, except for sensitivity to Alternaria fungus which was significantly more common in winter, there was no significant relationship between sensitivity to allergens and patients' referring season. In another study conducted in Spain, it was indicated that between April and June, and July and September, the prevalence of grass and olive tree allergens and Russian thistle allergen, has been higher than other months, respectively [29]. Moreover, the study conducted in Mexico showed that tree pollens and grasses and weeds pollens are more common during the dry winter and summer, respectively. About $30 \%$ of our patients did not have positive reactions.

These differences may be indicative of different weather conditions in each region and diverse phytogeography in different areas of the world. According to the climatic conditions of Qazvin province and seasonal distribution of some allergens, it is not unexpected to observe seasonal patterns of the incidence of symptoms in some types of allergens (such as Alternaria fungus and other allergens which were not reviewed in this study) or may be due to changes that had occurred in the skin responses because of new and nonspecific dust that lead to allergic symptoms but did not examine in this study.

In this study, according to the highest prevalence of allergies to weed pollens (Russian thistle) and grass (12 grasses) from among plant allergens, and beetle and Alternaria fungus from among non-plant allergens, properly training of the patients about avoiding contact with these agents as the most important way to prevent and treat as well as informing about allergy symptoms, all are effective in prevention and reduction of the severity of symptoms in patients. Furthermore, using immunotherapy for desensitization to common allergens will have a significant effect on the symptoms to be completely disappeared.

\section{Acknowledgment}

This paper is result of the M.D. thesis no. 838 in Qazvin University of Medical Sciences. The present study was ethically confirmed by committee of research, Department of Qazvin Medical School. We deeply thank the staff of research, Department of Qazvin Medical School for their support.

\section{References}

1. Singh AB, Kumar $P$ (2003) Aeroallergens in clinical practice of allergy in India An overview. Ann Agric Environ Med 10: 131-136.

2. Violeta VB, Naser B, Besa L, Ganimete B, Luljeta A (2010) Sensitivity to pollen allergens in consecutive patients with allergic rhinitis referred to an allergy clinic in Prishtina. Macedonian Journal of Medical Sciences 2: 121-125

3. Johnston FH, Hanigan IC, Bowman DM (2009) Pollen loads and allergic rhinitis in Darwin, Australia: A potential health outcome of the grass-fire cycle. Ecohealth 6: 99-108.

4. Barber D, de la Torre F, Feo F, Florido F, Guardia P, et al. (2008) Understanding patient sensitization profiles in complex pollen areas: a molecular epidemiological study. Allergy 63: 1550-1558. 
Citation: Mahram M, Barikani A, Nejatian N (2013) The Frequency of Common Allergens in Allergic Rhinitis among the Patients Referred to the Allergy Clinic of Qods Hospital in Qazvin during 2007-2010. J Aller Ther 4: 130. doi:10.4172/2155-6121.1000130

5. Port A, Hein J, Wolff A, Bielory L (2006) Aeroallergen prevalence in the northern New Jersey-New York City metropolitan area: a 15-year summary. Ann Allergy Asthma Immunol 96: 687-691.

6. Milgrom H, Leung D (2007) Allergic rhinitis. In: Kliegman RM, Behrman RE, Jenson HB, Stanton BF, Nelson text book of Pediatrics (18thedn), North of America: Saunders.

7. Kashef S, Kashef MA, Eghtedari F (2003) Prevalence of aeroallergens in allergic rhinitis in shiraz. Iran J Allergy Asthma Immunol 2: 185-188.

8. Ahmadiafshar A, Farhoodi A, Atarod L, Poorpak M, Bazargan N (2002) Mite the most common allergen in allergic respiratory tract disorders in children. Proceeding in 6th Iranian congress of Immunology and Allergy. Iranian Journal of Allergy, Asthma and Immunology.

9. Movahedi M, Moin M, Farhoudi A (2000) A comparison between diagnostic clinical tests and herbal geography in allergic patients in Tehran and Karaj cities. Iranian Journal of Allergy, Asthma and Immunology: 29-31.

10. Akbari H, Rezaei A (2000) Common allergens for allergic patients in Isfahan: A clinically-Based study. J Res Med Sci.

11. Behmanesh F, Shoja M, Khajedaluee M (2010) Prevalence of Aeroallergens in Childhood Asthma in Mashhad. Macedonian Journal of Medical Sciences 3: $295-298$.

12. Bhargava RK, Gupta B (1982) Seasonal blistering dermatitis. J Indian Med Assoc 79: 98-99

13. Fleisher TL, Fox I (1970) Oedemerid beetle dermatitis. Arch Dermatol 101: 601 605.

14. Southcott RV (1989) Injuries from Coleoptera. Med J Aust 151: 654-659.

15. Ahmed AR, Moy R, Barr AR, Price Z (1981) Carpet beetle dermatitis. J Am Acad Dermatol 5: 428-432.

16. McCrae AW, Visser SA (1975) Paederus (Coleoptera: Staphylinidae) in Uganda. I: Outbreaks, clinical effects, extraction and bioassay of the vesicating toxin. Ann Trop Med Parasitol 69: 109-120.

17. Nikbakhtzadeh MR, Tirgari S (2008) Medically important beetles (insecta: coleoptera) of Iran. Journal of Venomous Animals and Toxins including Tropical Diseases 14
18. Terán LM, Haselbarth-López MM, Quiroz-García DL (2009) Allergy, pollen and the environment. Gac Med Mex 145: 215-222.

19. Alaouie M (2009) Identification of aeroallergens in Lebanon. Asia pacific aeroallergen working group-WAO Newsletter 2: 2.

20. Sakashita M, Hirota T, Harada M, Nakamichi R, Tsunoda T, et al. (2010) Prevalence of allergic rhinitis and sensitization to common aeroallergens in a Japanese population. Int Arch Allergy Immunol 151: 255-261.

21. Sanli A, Aydin S, Ates G, Eken G, Celebi O (2006) Comparison of nasal smear eosinophilia with skin prick test positivity in patients with allergic rhinitis. Kulak Burun Bogaz Ihtisas Derg 16: 60-63.

22. Demoly P, Piette V, Bousquet J (2003) In vivo methods for study of allergy. In Adkinson NF, Yunginger JW, Busse WW, Bochner BS, Holgate ST, Simsons FE, editors. Middleton's allergy principles and Practice (6thedn) Mosby: Philadelphia 631-640.

23. Gardon A (1998) Allergy skin tests for inhalant allergy testing and immunotherapy. Otolaryngol Clin North Am 1: 11-23.

24. Gendeh BS, Mujahid SH, Murad S, Rizal M (2004) Atopic sensitization of children with rhinitis in Malaysia. Med J Malaysia 59: 522-529.

25. Kidon MI, See Y, Goh A, Chay OM, Balakrishnan A (2004) Aeroallergen sensitization in pediatric allergic rhinitis in Singapore: is air-conditioning a factor in the tropics? Pediatr Allergy Immunol 15: 340-343.

26. Pumhirun $P$, Towiwat $P$, Mahakit $P$ (1997) Aeroallergen sensitivity of Tha patients with allergic rhinitis. Asian Pac J Allergy Immunol 15: 183-185.

27. Sener O, Kim YK, Ceylan S, Ozanguc N, Yoo TJ (2003) Comparison of skin tests to aeroallergens in Ankara and Seoul. J Investig Allergol Clin Immunol 13: 202-208.

28. Benzarti M, Mezghani S, Jarray M, Garrouche A, Khirouni S, et al. (2002) Skin test reactivity to seven aeroallergens in a Sousse area population sample. Tunis Med 80: 450-454.

29. Subiza Garrido-Lestache J (2004) Allergenic pollens in Spain. Allergo Immunopathol (Madr) 32: 121-124.

30. Aburuz S, Bulatova N, Tawalbeh M (2011) Skin prick test reactivity to aeroallergens in Jordanian allergic rhinitis patients. East Mediterr Health $\mathrm{J} 17$ : 604-610. 